\title{
Effects of formoterol and salmeterol on cytokine release from monocyte-derived macrophages
}

\author{
L.E. Donnelly, S.J. Tudhope, P.S. Fenwick and P.J. Barnes
}

ABSTRACT: Pulmonary macrophages are a target for inhaled therapies. Combinations of longacting $\beta_{2}$-agonists (LABA) and glucocorticosteroids have been developed for asthma and chronic obstructive pulmonary disease (COPD). This study examined two LABA, salmeterol and formoterol, and the glucocorticosteroid, budesonide, on cytokine release from monocytederived macrophages (MDM) to determine whether anti-inflammatory effects observed in patients are due to inhibition of macrophages.

MDM were incubated in the absence or presence of LABA or budesonide prior to stimulation with lipopolysaccharide (LPS). Tumour necrosis factor (TNF)- $\alpha$, granulocyte macrophage-colony stimulating factor (GM-CSF) and CXC chemokine ligand (CXCL)8 were measured by ELISA.

Formoterol and salmeterol inhibited LPS-stimulated release of TNF- $\alpha$ (mean effective concentration (EC50) $2.4 \pm 1.8$ and $3.5 \pm 2.7 \mathrm{nM}$, respectively; $\mathrm{n}=11-16$ ), GM-CSF (EC50 24.6 \pm 2.1 and $52.4 \pm 40.8 \mathrm{nM}$, respectively, $n=11-12)$ but not CXCL8 from LPS-stimulated MDM. Budesonide inhibited release of all three cytokines (EC50 TNF- $\alpha$ : $1.2 \pm 0.4 \mathrm{nM}$; GM-CSF: $0.4 \pm 0.2 \mathrm{nM}$; CXCL8: $0.4 \pm 0.1 \mathrm{nM}$; $\mathbf{n}=3-4)$. Formoterol but not salmeterol elevated cAMP in these cells. These effects were attenuated by $\beta$-adrenoceptor antagonists, propranolol and ICI118551. Salmeterol $\left(10^{-7} \mathrm{M}\right)$ also inhibited formoterol-induced cAMP and formoterol-mediated attenuation of cytokine release. Combining budesonide $(0.3 \mathrm{nM})$ with formoterol, inhibited TNF- $\alpha$ release additively.

LABA may inhibit inflammatory cytokine release from macrophages in a cAMP-independent manner and act additively with budesonide.

KEYWORDS: Budesonide, inflammation, long-acting $\beta_{2}$-agonists, macrophage, tumour necrosis factor- $\alpha$

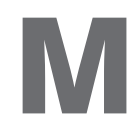
acrophages are the predominant leukocytes in the lung and have a role in homeostasis [1, 2]. Alveolar macrophages are the sentinel cells of the airways, patrolling the lung surface and scavenging any inhaled particles and pathogens and removing apoptotic cells and other debris. This macrophage function suggests that these cells would be prime targets for inhaled pharmaceutical agents. Current inhaled pharmacotherapies include bronchodilators, such as $\beta_{2}$-agonists, and anti-inflammatory agents, such as glucocorticosteroids. Another role of the macrophage is to respond to the local environment to produce a number of mediators including cytokines and chemokines. Macrophages respond to a number of pro-inflammatory stimuli, including lipopolysaccharide (LPS)-producing inflammatory mediators including tumour necrosis factor (TNF)- $\alpha$, granulocyte macrophage-colony stimulating factor (GM-CSF) and interleukin (IL) CXCL8 [3]. Therefore, these cells have the potential to drive the chronic inflammation observed in a number of lung diseases.

Lung macrophage numbers are increased by more than 20-fold in chronic obstructive pulmonary disease (COPD) and could account for many of the pathophysiological features of COPD [4]. The inflammatory response in COPD is associated with increased expression of inflammatory cytokines. Indeed, levels of TNF- $\alpha$ and CXCL8 are elevated in the sputum of patients with COPD compared with control subjects [5-7]. Similarly, GM-CSF levels are raised in the bronchoalveolar lavage of patients with chronic bronchitis compared with controls and are elevated during exacerbations [8,9]. The precise source of these inflammatory cytokines is

\section{AFFILIATIONS}

Airway Disease, National Heart and Lung Institute, Imperial College London, London, UK.

\section{CORRESPONDENCE}

L.E. Donnelly

Airway Disease, National Heart and Lung Institute

Imperial College London

Dovehouse Street

London

SW3 6LY

UK

E-mail: I.donnelly@imperial.ac.uk

Received:

Oct 202008

Accepted after revision:

Nov 012009

First published online:

Nov 192009 
unknown; however, it is possible that macrophages might be an important source of these cytokines in disease [10]. Although alveolar macrophage numbers are not as pronounced in asthma, they also have the capacity to contribute to the increased inflammatory cytokine load observed in the lungs of these patients. In particular, alveolar macrophages from asthmatic subjects release IL-1 $\beta$ and IL-6 [11], which, in turn, stimulate cluster of differentiation (CD)4+ T-cells to produce IL-5 and hence may contribute to the eosinophilic load associated with asthma.

$\beta_{2}$-Agonists are administered to patients primarily for their bronchodilatory effects; however, they may also impact upon inflammation since eicosanoids and IL-1 $\beta$ release from stimulated human peripheral blood monocytes can be inhibited by $\beta_{2}$-agonists [12]. However, the anti-inflammatory effects of these drugs on macrophages are less clear. Neither the short-acting $\beta_{2}$-agonists, salbutamol or terbutaline, nor the long-acting $\beta_{2}$-agonists (LABA), salmeterol or formoterol, inhibit LPS-stimulated IL- $\beta$ release from alveolar macrophages [13]. Similarly, neither salmeterol nor formoterol have any effect on of LPS-stimulated release of C-C motif chemokine 22 (macrophage-derived chemokine) or CXCL10 (interferon- $\gamma$ inducible protein of $10 \mathrm{kDa}$ ) from differentiated THP-1 cells [14]. However, salmeterol inhibits thromboxane release from human alveolar macrophages [15]. As cAMP-elevating agents, including phosphodiesterase inhibitors, show anti-inflammatory effects in monocytes and macrophages [16, 17], it is possible that $\beta_{2}$-agonists would have similar effects.

Although glucocorticosteroids are effective anti-inflammatory treatments for asthma, they are considerably less effective in reducing the underlying inflammation associated with COPD [18]. Recently, combinations of LABA and glucocorticosteroids have been shown to slow the rate of decline of lung function in COPD patients above the effects of each of the components alone $[19,20]$. Combinations of glucocorticosteroids and $\beta_{2^{-}}$ agonists have been shown to act both synergistically and additively. For example, $\beta_{2}$-agonists increase nuclear localisation of glucocorticoid receptors (GR) and subsequent DNA binding in primary human lung fibroblasts, resulting in increased steroid-dependent gene transcription [21]. Salmeterol also enhances glucocorticosteroid-dependent inhibition of allergen-induced cytokine release from peripheral blood mononuclear cells [22] and TNF- $\alpha$-induced expression of intercellular adhesion molecule 1 in fibroblasts [23]. In addition, low concentrations of formoterol increase the suppressive effect of budesonide on the release of TNF- $\alpha$-induced GM-CSF from cultured human airway epithelial cells [24].

As the macrophage is very likely to interact with inhaled drugs that have the potential to regulate inflammatory cytokine production from these cells, we have examined the efficacy of two LABA, formoterol and salmeterol, on the release of TNF- $\alpha$, GM-CSF and CXCL8 from LPS-stimulated monocyte-derived macrophages (MDM). LPS-stimulation was used as a surrogate for gram-negative bacterial stimulus. The lower respiratory tract of many patients with COPD is colonised with gram-negative bacteria [25] and hence is relevant stimulus for this study. MDM differentiated in the presence of GM-CSF are phenotypically similar to alveolar macrophages [26] and we have shown they respond similarly to human lung macrophages [3].
In addition, we have compared the responses of these agents with those of the glucocorticosteroid, budesonide, to ascertain whether inhibiting macrophages may contribute to the efficacy of these drugs in the patient.

\section{MATERIALS AND METHODS \\ Materials}

All reagents were obtained from Sigma (Poole, Dorset, UK), unless otherwise stated. Budesonide and formoterol were kind gifts from AstraZeneca (Lund, Sweden) and prepared in DMSO at a stock concentration of $10 \mathrm{mM}$; the maximum concentration of DMSO in the cell treatments was $0.1 \%$ (volume/volume). Salmeterol was prepared as a $50 \mathrm{mM}$ stock in methanol; the maximum concentration of methanol in the cell treatments was $0.002 \%(\mathrm{v} / \mathrm{v})$.

\section{Culture of MDM}

Whole blood was collected from healthy volunteers from the National Heart and Lung Institute (Imperial College London, London, UK). All subjects were nonsmokers, had normal lung function with no history of lung disease. This study was approved by the Imperial College Research Ethics Committee. Blood was collected in $2 \mathrm{mg} \cdot \mathrm{mL}^{-1}$ EDTA and peripheral blood mononuclear cells (PBMC) isolated following dextran $(6 \%$ (weight/volume)) sedimentation and separation using a discontinuous Percoll gradient as previously described [27]. Cells were resuspended in RPMI 1640 medium supplemented with $2 \mathrm{mM}$ L-glutamine $10,000 \mathrm{U} \cdot \mathrm{mL}^{-1}$ penicillin, $10 \mathrm{mg} \cdot \mathrm{mL}^{-1}$ streptomycin and $10 \%(\mathrm{v} / \mathrm{v})$ fetal bovine serum (Invitrogen, Paisley, UK) and seeded into 24-well tissue culture plates at a density of $1 \times 10^{6}$ cells $\cdot$ well $^{-1}$. Monocytes were isolated from the PBMC fraction by adherence on to cell culture plates for $1 \mathrm{~h}$. After this time, the nonadherent cells were removed by aspiration and media replaced with RPMI 1640 medium supplemented with $2 \mathrm{mM}$ L-glutamine, $10,000 \mathrm{U} \cdot \mathrm{mL}^{-1}$ penicillin, $10 \mathrm{mg} \cdot \mathrm{mL}^{-1}$ streptomycin, $10 \%(\mathrm{v} / \mathrm{v})$ fetal bovine serum and $2 \mathrm{ng} \cdot \mathrm{mL}^{-1} \mathrm{GM}-\mathrm{CSF}$. Cells were cultured for 12 days in this differentiation media with media changes on day 4 and day 7 . Cells were considered MDM on day 12 .

\section{Cytokine measurements}

After 12 days of differentiation, cells were washed with Hank's balanced salt solution (HBSS) and media containing the drug under investigation (either $\beta_{2}$-agonists or budesonide) prior to stimulation with $10 \mathrm{ng} \cdot \mathrm{mL}^{-1}$ LPS (from Salmonella enteritidis) for $20 \mathrm{~h}$. The drug remained in the cell culture media throughout the stimulation period. After this time, cytokines were measured by ELISA. CXCL8, TNF- $\alpha$ and GM-CSF were measured using matched pair antibodies according to the manufacturer's instructions (R\&D Systems Europe, Abingdon, UK). The detection limit of the CXCL8 and IL-6 assays were $31 \mathrm{pg} \cdot \mathrm{mL}^{-1}$, the TNF- $\alpha$ and GM-CSF assays were $15.5 \mathrm{pg} \cdot \mathrm{mL}^{-1}$ and the IL-1 $\beta$ assay $3.15 \mathrm{pg} \cdot \mathrm{mL}^{-1}$.

\section{Cell viability assay}

Cell viability was determined colourimetrically by measuring the reduction of the tetrazolium salt, MTT, to formazan by mitochrondial dehydrogenases. Cells treated with vehicle were considered the control and assigned $100 \%$ viability. None of the conditions used in this study altered cell viability significantly (data not shown). 

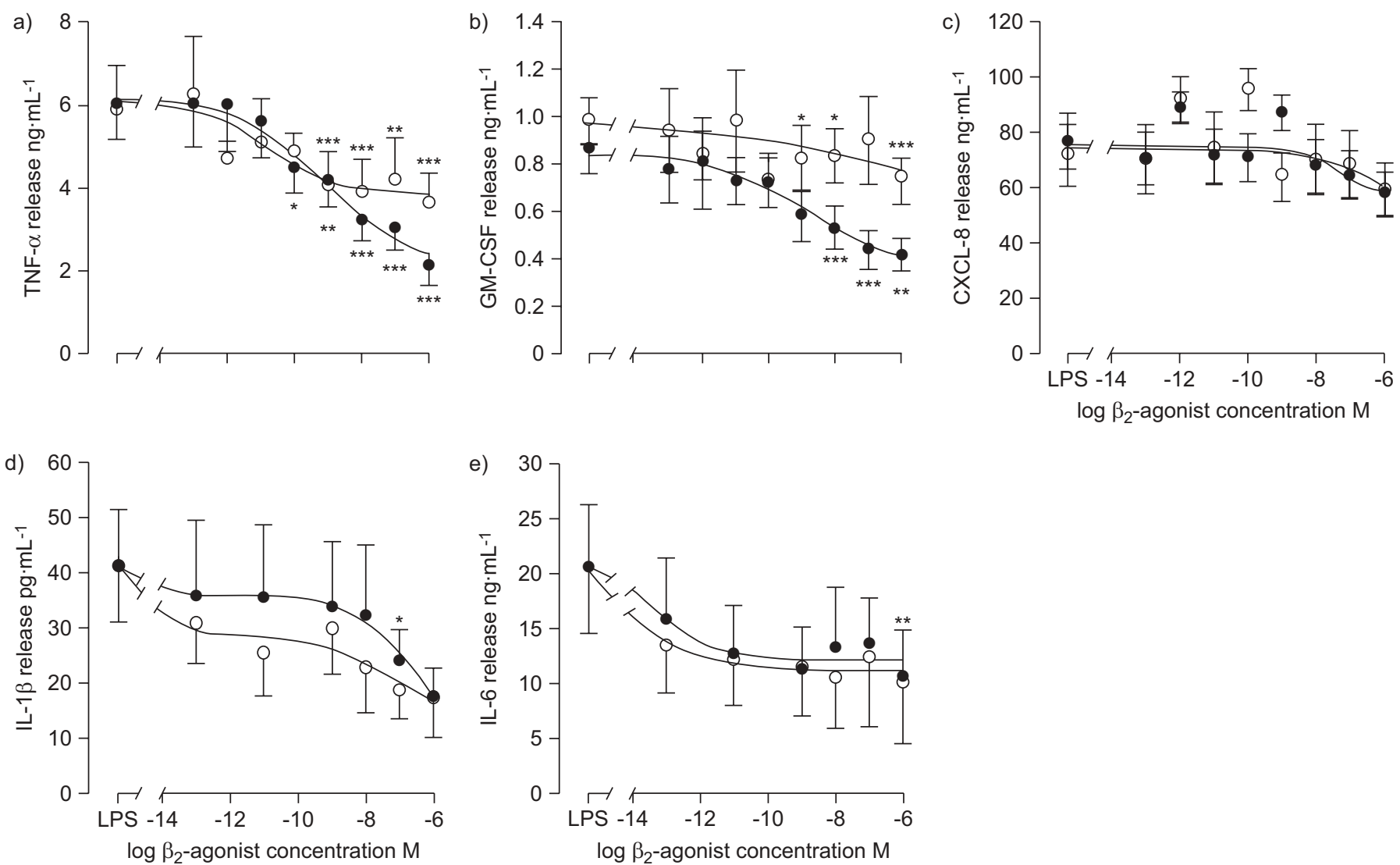

FIGURE 1. Effect of formoterol and salmeterol on lipopolysaccharide (LPS)-stimulated cytokine release from monocyte-derived macrophages (MDM). MDM were pretreated for $1 \mathrm{~h}$ with either formoterol $(\bullet)$ or salmeterol $(\bigcirc)$ prior to stimulation with $10 \mathrm{ng} \cdot \mathrm{mL}^{-1} \mathrm{LPS}$ for $20 \mathrm{~h}$. Cell media were harvested and concentrations of a) tumour necrosis factor (TNF)- $\alpha$, b) granulocyte macrophage-colony stimulating factor (GM-CSF), c) CXC chemokine ligand (CXCL)8, d) interleukin (IL)-1 $\beta$, and e) IL-6, were determined using ELISA. Data are presented as mean \pm SEM for $n=5-16$. ${ }^{* *}: p<0.001 ;{ }^{* *}: p<0.01 ;{ }^{*}: p<0.05$ for differences from LPS stimulation.

\section{Measurement of cAMP}

MDM were cultured in 24-well plates and incubated in modified HBSS buffer, containing calcium and magnesium, with $0.5 \%(\mathrm{w} / \mathrm{v})$ bovine serum albumin (BSA). The cells were pre-incubated for $1 \mathrm{~h}$ with buffer containing $100 \mu \mathrm{M} \mathrm{3-}$ isobutyl-1-methylxanthine (IBMX), prior to the addition of $\beta_{2}$-agonists and IBMX remained in the media throughout the experiment. Formoterol $\left(10^{-13}-10^{-6} \mathrm{M}\right)$ and salmeterol $\left(10^{-13}\right.$ $\left.10^{-6} \mathrm{M}\right)$ were incubated with cells for a further 2 mins. Cells were then lysed with $0.1 \mathrm{M} \mathrm{HCl}$ containing $0.5 \%(\mathrm{v} / \mathrm{v})$ tritonX100. Prostaglandin (PG) $\mathrm{E}_{2}$ at $10^{-6} \mathrm{M}$ was used as a positive control. Samples were stored at $-80^{\circ} \mathrm{C}$ until required. The levels of cAMP in the samples were measured using a commercially available enzyme immunoassay kit, according to the manufacturer's instructions (Biomol International UK, Exeter, UK). The lower limit of detection of the assay was $0.781 \mathrm{pmol} \cdot \mathrm{mL}^{-1}$ cAMP.

\section{Statistics}

Data are presented as mean \pm SEM for $n$ donors. Concentrationresponse curves were analysed by least-squares, non-linear iterative regression using the "GraphPad Prism" curve fitting program (GraphPad software, San Diego, CA, USA) and mean effective concentration (EC50) values were subsequently interpolated from curves of best-fit. Statistical differences were determined using the Kruskal-Wallis test followed by Dunn's multiple comparison test or a Mann-Whitney test as appropriate. Values of $\mathrm{p}<0.05$ were considered significant. Estimates of antagonist affinity $\left(\mathrm{p} K_{\mathrm{B}}\right)$ were calculated as described by SCHILD [28] using the equation $\mathrm{p} K_{\mathrm{B}}=\log (\mathrm{CR}-1)-\log [\mathrm{B}]$, where $\mathrm{CR}$ is the concentration ratio calculated as EC50 of agonist in the presence of antagonist divided by the EC50 of the agonist alone and [B] is the concentration of the antagonist [29].

\section{RESULTS}

MDM were stimulated with a sub-maximal concentration of LPS $\left(10 \mathrm{ng} \cdot \mathrm{mL}^{-1}\right)$ and the effect of the $\beta_{2}$-agonists, formoterol and salmeterol, on the release of TNF- $\alpha$, GM-CSF and CXCL8 was evaluated. Formoterol and salmeterol inhibited LPSstimulated TNF- $\alpha$ release from MDM with EC50 values of $2.4 \pm 1.8 \mathrm{nM}(\mathrm{n}=16)$ and $3.5 \pm 2.7 \mathrm{nM}(\mathrm{n}=11)$; with a significantly greater inhibition with formoterol than salmeterol at $10^{-6} \mathrm{M}(\mathrm{p}<0.05)$ of $66.5 \pm 3.9$ and $44.8 \pm 8 \%$, respectively (fig. 1a) with significant inhibition with formoterol occurring at $0.1 \mathrm{nM}$ and $1 \mathrm{nM}$ for salmeterol. Both $\beta_{2}$-agonists also inhibited the release of GM-CSF from these cells with EC50 values of $24.6 \pm 2.1 \mathrm{nM} \quad(n=12)$ for formoterol and $52.4 \pm 40.8 \mathrm{nM}(\mathrm{n}=11)$ for salmeterol (fig. 1b). Again, formoterol was more effective at inhibiting LPS-stimulated GM-CSF release from MDM than salmeterol (fig. 1b). By contrast, 

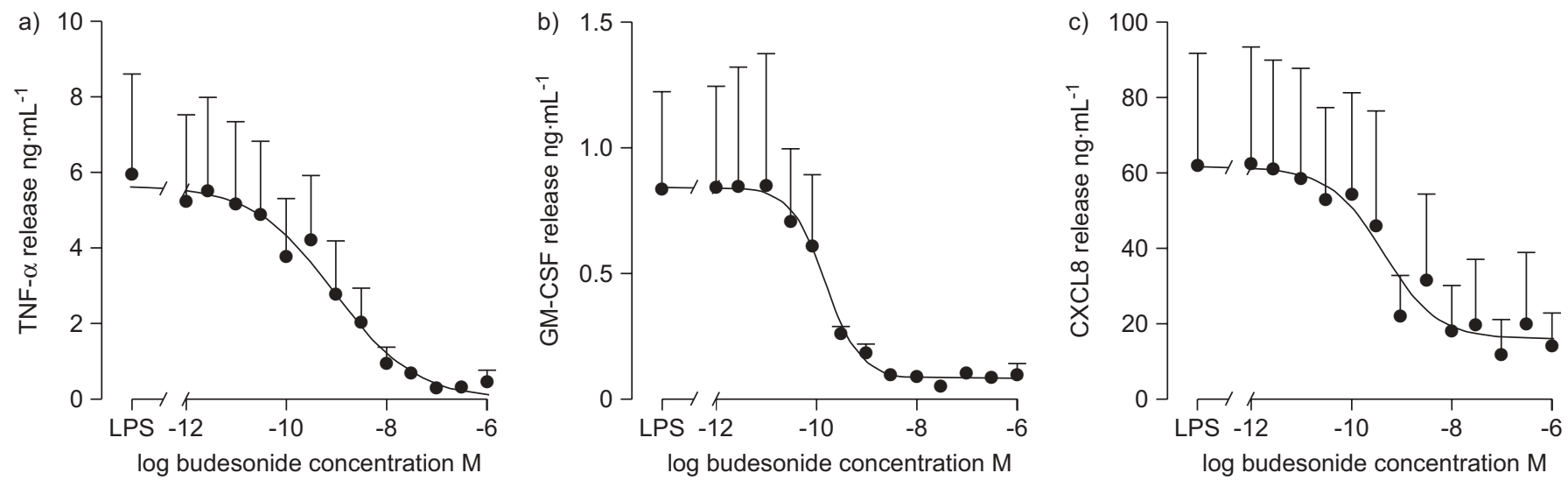

FIGURE 2. Effect of budesonide on lipopolysaccharide (LPS)-stimulated cytokine release from monocyte-derived macrophages (MDM). MDM were pre-treated for $1 \mathrm{~h}$ with budesonide prior to stimulation with $10 \mathrm{ng} \cdot \mathrm{mL}^{-1}$ LPS for $20 \mathrm{~h}$. Cell media were harvested and concentrations of a) tumour necrosis factor (TNF)- $\alpha, \mathrm{b}$ ) granulocyte macrophage-colony stimulating factor (GM-CSF), and c) CXC chemokine ligand (CXCL)8, were determined using ELISA. Data are presented as mean \pm SEM for $n=3-4$.

neither formoterol nor salmeterol inhibited the release of CXCL8 from these cells (fig. 1c). Both formoterol and salmeterol inhibited LPS-stimulated IL-1 $\beta$ release from these cells with EC50 values of $110 \pm 84 \mathrm{nM}(\mathrm{n}=5)$ and $28 \pm 21 \mathrm{nM}(\mathrm{n}=5)$, respectively; and also IL-6 release with EC50 values of $2.5 \pm 2.4 \mathrm{pM} \quad(\mathrm{n}=5)$ and $0.04 \pm 0.01 \mathrm{pM}(\mathrm{n}=5)$, respectively. The limited inhibitory effects of $\beta_{2}$-agonists on LPS stimulation of MDM was not due to this cellular model being resistant to inhibition since TNF- $\alpha$, GM-CSF and CXCL8 release from these cells were all inhibited by $>80 \%$ by the addition of budesonide (fig. 2), with EC50 values of $1.2 \pm 0.4 \mathrm{nM}(\mathrm{n}=4), 0.4 \pm 0.2 \mathrm{nM}$ $(\mathrm{n}=4)$ and $0.4 \pm 0.1 \mathrm{nM}(\mathrm{n}=3)$, respectively.

Elevation of intracellular levels of cAMP can lead to inhibition of inflammatory gene transcription; therefore, it was possible that the differential effects of formoterol and salmeterol on the inhibition of cytokine release from LPS-stimulated MDM were due to differences in their capacity to increase cAMP levels in these cells. Experiments were performed in the presence of IBMX $(100 \mu \mathrm{M})$. Formoterol stimulated accumulation of cAMP in MDM $(\mathrm{EC} 50=1.6 \pm 0.3 \mathrm{nM} ; \mathrm{n}=5)$ but exposure of the cells to salmeterol did not alter cAMP levels at any of the concentrations examined $\left(10^{-13}-10^{-6} \mathrm{M}\right)$ (fig. 3a). Time courses of $\leqslant 15 \mathrm{~min}$ were performed but salmeterol failed to elevate cAMP in this system (data not shown). To ascertain that the effect of formoterol was via activation of $\beta$-receptors, cells were pre-treated with either the nonselective $\beta$-adrenoceptor antagonist propranolol $\left(10^{-7} \mathrm{M}\right)$ or the selective $\beta_{2}$-adrenoceptor antagonist ICI118551 $\left(10^{-7} \mathrm{M}\right)$ prior to exposure to formoterol. Both antagonists abrogated formoterol-mediated elevation of cAMP (fig. 3b) suggesting that formoterol was acting via a $\beta_{2}$-adrenoceptor.

The inability of salmeterol to increase levels of cAMP in MDM prompted investigation as to whether, in these cells; salmeterol could act as an antagonist. To examine this possibility, MDM were pre-treated with $10^{-7} \mathrm{M}$ salmeterol prior to stimulation with formoterol $\left(10^{-13}-10^{-6} \mathrm{M}\right)$. Pre-treatment of MDM with salmeterol for $30 \mathrm{~min}$ did not increase cAMP significantly above baseline levels (baseline: $0.56 \pm 0.14 \mathrm{pmol} \cdot \mathrm{mL}^{-1} \quad(n=4)$ versus salmeterol: $\left.1.7 \pm 0.4 \mathrm{pmol} \cdot \mathrm{mL}^{-1}(\mathrm{n}=4)\right)$. However, salmeterol inhibited formoterol-induced accumulation of cAMP
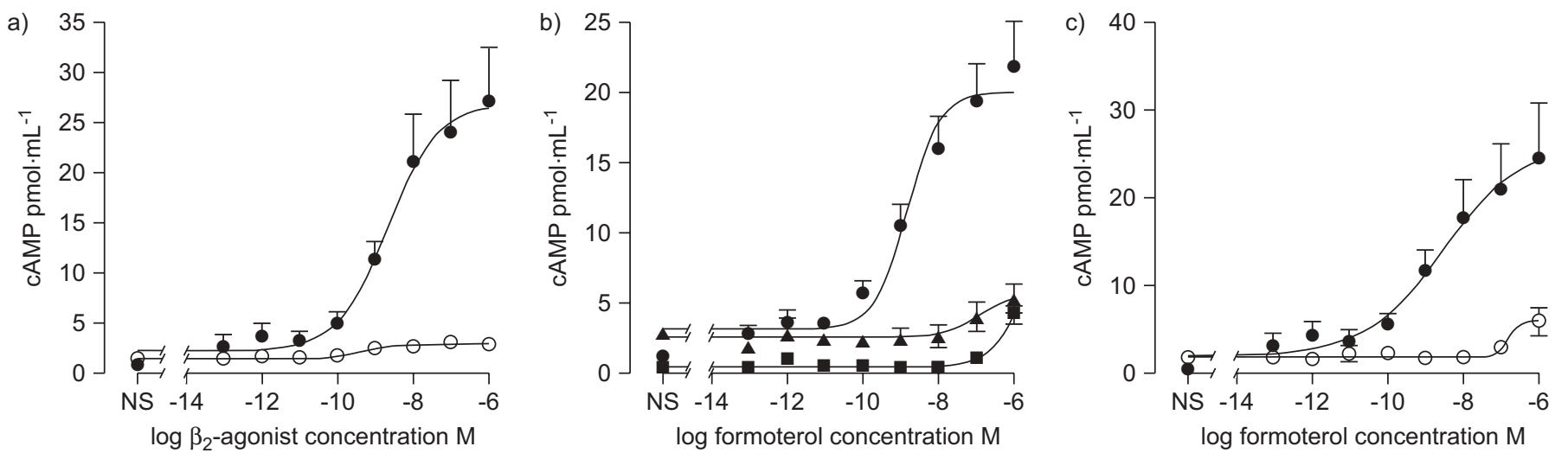

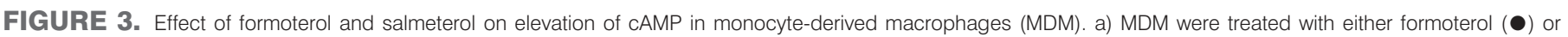

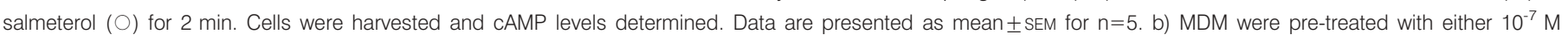

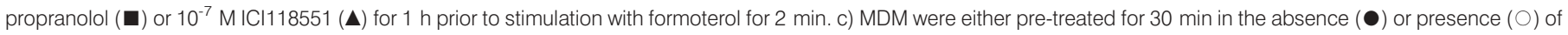

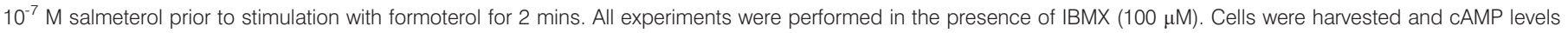
determined. Data are presented as mean \pm SEM for $n=3-8$. 

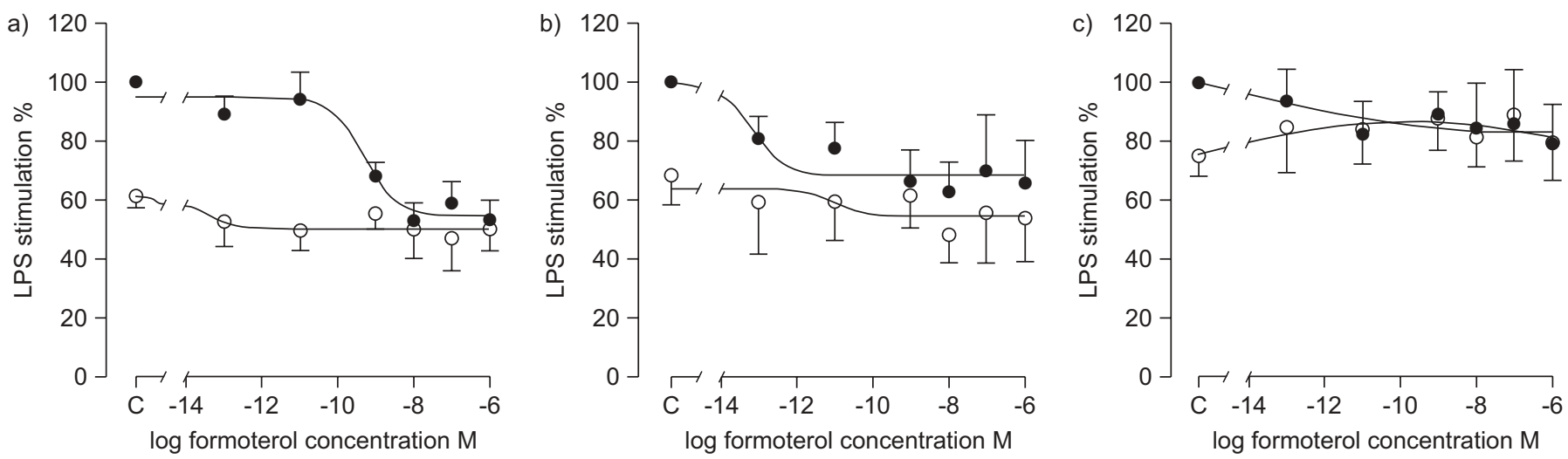

FIGURE 4. Effect of salmeterol on formoterol-mediated inhibition of lipopolysaccharide (LPS)-stimulated cytokine release from monocyte-derived macrophages (MDM) MDM were either pre-treated for $30 \mathrm{~min}$ in the absence $(\bullet)$ or presence $(O)$ of $10^{-7} \mathrm{M}$ salmeterol prior to incubation with formoterol for a further $1 \mathrm{~h}$. Cells were stimulated with $10 \mathrm{ng} \cdot \mathrm{mL}^{-1}$ LPS for $20 \mathrm{~h}$, media harvested and the concentrations of a) tumour necrosis factor- $\alpha$, b) granulocyte macrophage-colony stimulating factor, and c) CXC chemokine ligand 8 were determined by ELISA. Data are presented as mean \pm SEM, $n=6$, where $100 \%$ is the maximal stimulation with LPS. C: control.

in MDM (fig. 3c). These data suggested that salmeterol, which is a partial agonist, could act antagonistically at the $\beta_{2}$-receptor. Therefore, the effect of salmeterol to attenuate the inhibitory effects of formoterol on cytokine release was evaluated. MDM were pre-treated with $10^{-7} \mathrm{M}$ salmeterol prior to exposure to formoterol then stimulated with LPS and cytokines measured. This concentration of salmeterol inhibited TNF- $\alpha$ by $\sim 40 \%$, GM-CSF by $\sim 30 \%$ and CXCL8 by $\sim 20 \%$ (fig. 4 ). However, despite inhibiting the accumulation of formoterol-stimulated cAMP in MDM (fig. 3c), the addition of formoterol following salmeterol pre-incubation did not result in further inhibition of LPS-stimulated cytokine release (fig. 4). To further investigate the mechanism underlying the differential inhibitory effects of formoterol and salmeterol, MDM were stimulated with LPS for $20 \mathrm{~h}$ following $30 \mathrm{~min}$ pre-treatment with a phosphodiesterase (PDE) inhibitor, rolipram $(10 \mu \mathrm{M})$ in the presence of either formoterol or salmeterol and the release of TNF- $\alpha$ measured. Inhibition of PDE enhanced the inhibitory effect of formoterol (fig. 5a) but not salmeterol (fig. 5b). LPS stimulation of these cells was unlikely to be generating other, endogenous agents (e.g. prostaglandin $\mathrm{E}_{2}$ ) that could contribute to the inhibitory effects observed, as there was no difference in the level of TNF- $\alpha$ released from these cells following stimulation with LPS in the absence or presence of rolipram $(11.9 \pm 3.3$ versus $\left.12.3 \pm 4.4 \mathrm{ng} \cdot \mathrm{mL}^{-1} ; \mathrm{n}=4\right)$.

The possibility that formoterol-mediated inhibition of LPSstimulated cytokine release from MDM was not mediated via the $\beta$-adrenoceptor was investigated using propranolol and ICI118551. However, both antagonists attenuated the inhibitory action of formoterol on the release of LPS-stimulated TNF- $\alpha$ from MDM (fig. 6) (EC50 formoterol $0.17 \pm 0.07 \mathrm{nM}$ $(\mathrm{n}=4)$; formoterol and propranolol $60.7 \pm 36.1 \mathrm{nM}(\mathrm{n}=3)$; and formoterol and ICI118551 22.7 $\pm 22.5 \mathrm{nM}(\mathrm{n}=4)$ ) with estimated $\mathrm{p} K_{\mathrm{B}}$ values of $9.0 \pm 0.7$ and $8.3 \pm 0.7$ for propranolol and ICI118551 respectively. This suggested that formoterol inhibits cytokine release via the $\beta_{2}$-adrenoceptor on MDM.

It has been reported that steroids and $\beta_{2}$-agonists can act either synergistically or additively to inhibit inflammatory cytokines in a variety of cell systems $[30,31]$. Therefore, we investigated
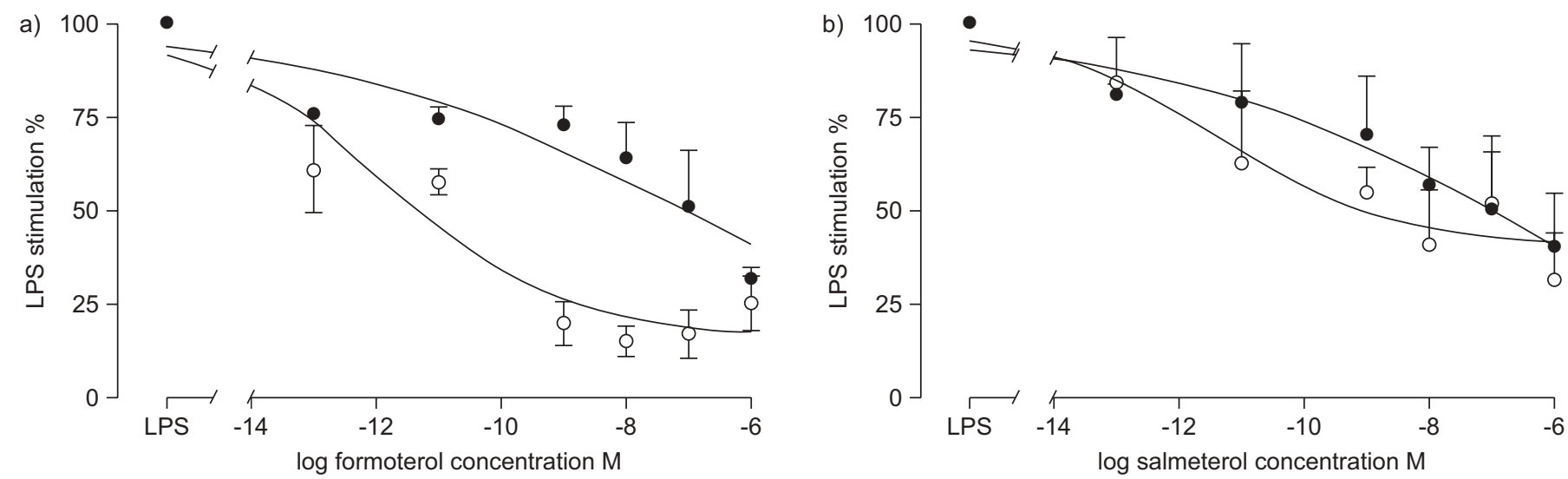

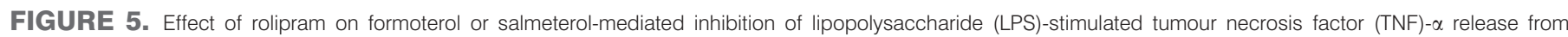
monocyte-derived macrophages (MDM). MDM were either pre-treated for 30 mins in the absence ) or presence $(O)$ of $0.3 \mathrm{nM}$ budesonide prior to incubation with

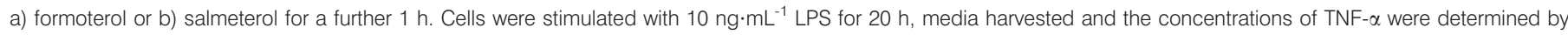
ELISA. Data are presented as mean $\pm \mathrm{SEM}, \mathrm{n}=4$. 


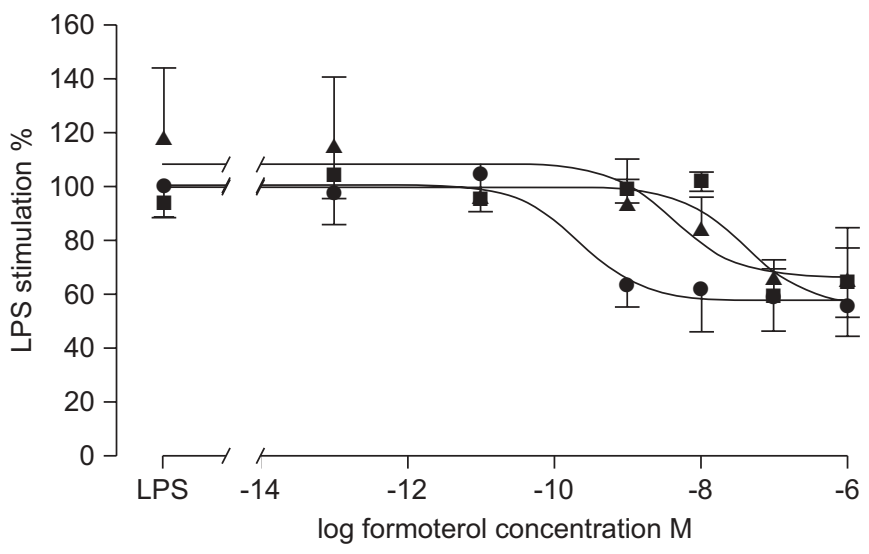

FIGURE 6. Effect of $\beta$-adrenoceptor antagonists on formoterol-mediated inhibition of lipopolysaccharide (LPS)-stimulated cytokine release from monocytederived macrophages (MDM). MDM were either pre-treated for $30 \mathrm{~min}$ in the

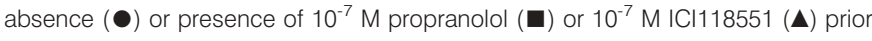
to incubation with formoterol for a further $1 \mathrm{~h}$. Cells were stimulated with $10 \mathrm{ng} \cdot \mathrm{mL}^{-1}$ LPS for $20 \mathrm{~h}$, media harvested and the concentrations of tumour necrosis factor- $\alpha$ were determined by ELISA. Data are presented as mean \pm SEM, $n=3-4$, where $100 \%$ is the maximal stimulation with LPS.

whether a low concentration of budesonide $(0.3 \mathrm{nM})$ would alter the anti-inflammatory effects of formoterol on LPSstimulated MDM. Budesonide alone $(0.3 \mathrm{nM})$ inhibited LPSstimulated TNF- $\alpha$, GM-CSF and CXCL8 release by $32.3 \pm 9.8 \%$ $(n=5), 61.3 \pm 11.2 \%(n=3)$ and $28.8 \pm 4.3 \%(n=4)$, respectively (fig. 7). Formoterol alone inhibited LPS-stimulated TNF- $\alpha$ and GM-CSF release with EC50 values of $0.2 \pm 0.1 \mathrm{nM}(\mathrm{n}=5)$ and $0.8 \pm 0.3 \mathrm{nM}(\mathrm{n}=3)$, respectively but there was no effect of formoterol on LPS-stimulated CXCL8 release from MDM. The combination of $0.3 \mathrm{nM}$ budesonide with formoterol inhibited TNF- $\alpha$, and GM-CSF release with EC50 values for formoterol of $1.1 \pm 1.0 \mathrm{nM}(n=5)$ and $1.6 \pm 1.5 \mathrm{nM}(\mathrm{n}=3)$, respectively (fig. $7 \mathrm{a}$ and $\mathrm{b}$ ) with no significant shifts in the formoterol response curves. The presence of budesonide did not alter the formoterol response to CXCL8 release from these cells (fig. 7c)

\section{DISCUSSION}

Alveolar macrophages will interact with inhaled pharmaceutical agents and, as such, are a good target for therapeutic interventions. Macrophages have been implicated in the pathophysiology of COPD [4] and may contribute to inflammatory load in asthma; therefore, many therapeutic approaches are being developed that aim to target these cells directly. Hence, it is important to understand how current pulmonary medications may interact with macrophages and whether these drugs could regulate the release of inflammatory mediators from these cells. Inflammation in COPD is associated with increased concentrations of cytokines including TNF- $\alpha$, GMCSF and CXCL8 [4]; therefore, this study examined the effects of LABA on the release of these mediators from LPS-stimulated macrophages together with IL-1 $\beta$ and IL-6 which may contribute to the pathophysiology of asthma. LPS was selected as a stimulus as it represents the presence of gram-negative bacteria. There are limitations to this approach, as the LPS used may not be of the strain found in the airway; nevertheless, LPS is considered the classical activator of macrophages and was used in this study as a pro-inflammatory stimulus [32].

This study demonstrated that the full $\beta_{2}$-agonist, formoterol, was more effective than the partial $\beta_{2}$-agonist, salmeterol, at inhibiting TNF- $\alpha$ and GM-CSF release from LPS-stimulated MDM. This concurs with studies examining the effects of these $\beta_{2}$-agonists on histamine release from mast cells and mediator release from eosinophils [33] where salmeterol is less efficacious than formoterol [34]. The data presented in this study differ from that observed in THP-1 cells that were differentiated towards a macrophage phenotype with phorbol myristate acetate, where neither formoterol nor salmeterol inhibit LPS-stimulated TNF- $\alpha$ release [14]. In the present study, neither of the $\beta_{2}$-agonists examined inhibited LPS-stimulated CXCL8 release from these macrophages. This would suggest that the reported effects of formoterol to reduced sputum
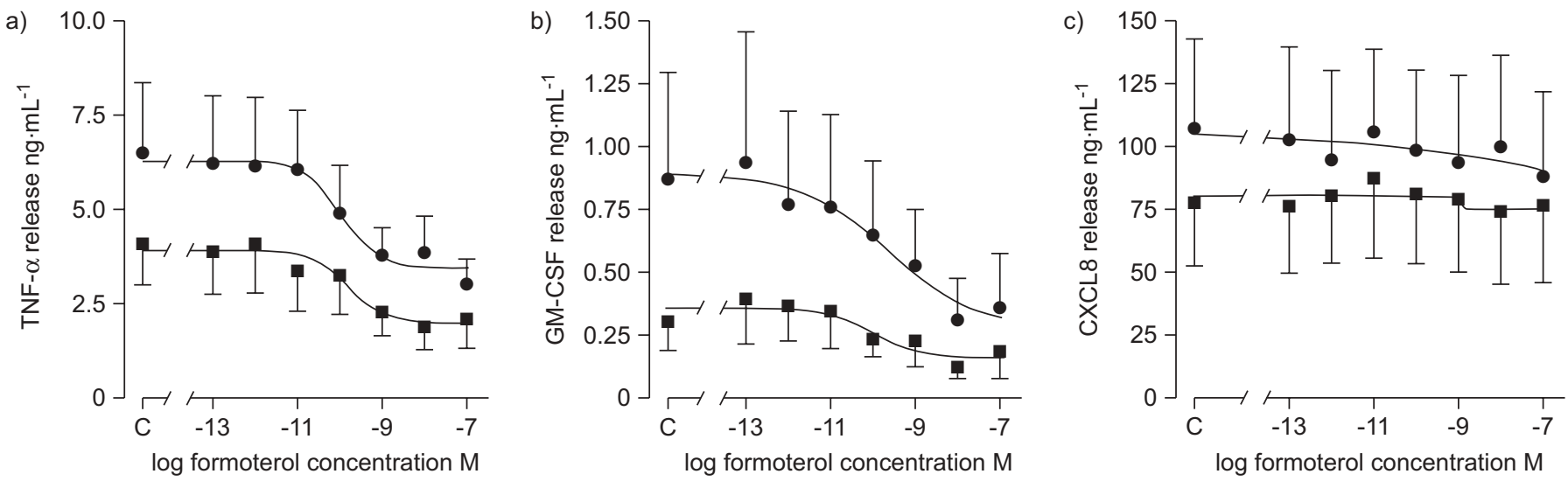

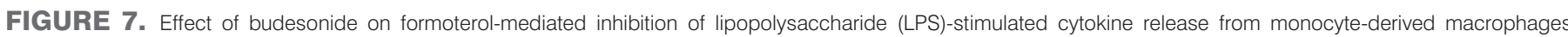

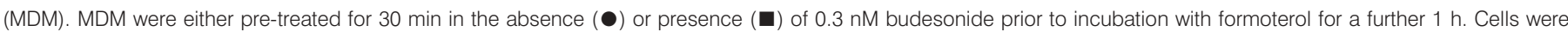

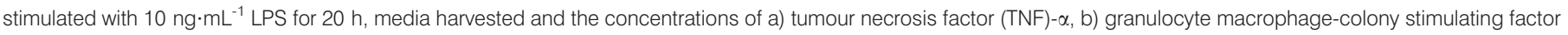
(GM-CSF), and C) CXC chemokine ligand (CXCL) 8 were determined by ELISA. Data are presented as mean \pm SEM, $n=3-5$. 
CXCL8 [35] and salmeterol to reduce bronchoalveolar lavage fluid CXCL8 in asthma [36] are not due to inhibition of macrophages. There was also inhibitory effect of both LABA on LPS-stimulated release of IL-1 $\beta$ and IL-6. The former contrasts with data presented for alveolar macrophages whereby LABA failed to inhibit LPS-stimulated IL- $\beta$ release from alveolar macrophages [13] and may highlight differences in this model system. However, the present study demonstrates differential effects of $\beta_{2}$-agonists on inflammatory mediator production from macrophages and this is not restricted to pro-inflammatory cytokines, since IL-6 can also be inhibited. The lack of effect of $\beta_{2}$-agonists on CXCL8 release has been shown previously in human primary smooth muscle cells stimulated with IL-1 $\beta$ [37]. LPS-stimulation of cytokine release is thought to be mediated via the activation of nuclear factor (NF)-кB [38], which can be inhibited by cAMP [39, 40], although we have shown that this is not the case for CXCL8. These data demonstrate that different inflammatory genes regulated by NF- $\mathrm{BB}$ are themselves differentially regulated by cAMP-elevating agents.

However, our study suggests that inhibition of inflammatory gene expression via $\beta_{2}$-agonists may not require elevation of cAMP. Salmeterol failed to elevate cAMP in this system similar to the effect reported in human airway smooth cells [41], yet could inhibit TNF- $\alpha$ and GM-CSF release, albeit to reduced levels compared with formoterol. The lack of a relationship between the inhibitory effect of salmeterol and cAMP elevation was further supported by the observation that inhibition of PDE could not enhance the inhibitory effect of salmeterol but increased formoterol mediated inhibition. Salmeterol also acted as an antagonist to prevent formoterol mediated elevation of cAMP in these cells. This observation that salmeterol can act as an antagonist at the $\beta_{2}$-adrenceptor has been reported previously in human eosinophils [42]. Similarly, pre-treatment of MDM with salmeterol blocked any further inhibition of TNF- $\alpha$ release from these cells in the presence of formoterol. The limited effect of salmeterol in this system suggests that $\beta_{2}$-adrenoceptor-mediated inhibition of cytokine release from macrophages is, in part, cAMP-independent and requires alternative signalling pathways. Recently, it has been demonstrated that $\beta$-adrenoceptors can switch coupling from Gs to Gi [43]; however, since formoterol elevates cAMP in MDM, this is an unlikely explanation in MDM. Alternative $\beta_{2^{-}}$ adrenoceptor signalling pathways have been proposed [44, 45]. For example, $\beta_{2}$-adrenoceptors coupling to $\mathrm{Gs}$ can mediate smooth muscle relaxation in a cAMP-independent manner [46, 47]. We have now demonstrated an anti-inflammatory effect of LABA; for example, formoterol is $\beta$-adrenoceptor-dependent but salmeterol can mediate a cAMP-independent mechanism in MDM. This may have clinical relevance, since the inhibitory effect of salmeterol against TNF- $\alpha$, with no concomitant increase in cAMP occurred from $1 \mathrm{nM}$, which is considered in the therapeutic range.

Recently, there has been growing interest in the mechanism(s) of the enhanced effects of combinations of LABA and glucocorticosteroids [48, 31]. In order to investigate whether macrophages could account for the enhanced anti-inflammatory effects of combinations of LABA and steroids, we examined the effect of a low dose $(0.3 \mathrm{nM})$ budesonide on the antiinflammatory actions of formoterol. It has been proposed that LABA act synergistically with steroids by a number of mechanisms. These include enhanced translocation of the GR to the nucleus [21, 49] leading to increase GR-dependent transcription [50]. One gene that is upregulated in this manner is mitogen-activated protein (MAP) kinase phosphatase-1, an inhibitor of MAP kinase signalling pathways [51]. Inhibition of MAP kinase signalling in LPS-stimulated MDM leads to attenuation of cytokine release [3] and could account for any synergistic effects of LABA and glucocorticosteroids. However, in this study, we observed additive effects of budesonide and formoterol indicating that inhibition of LPS-stimulated cytokine release is likely to occur via separate pathways in MDM. This suggests that macrophages are unlikely to account for any synergistic anti-inflammatory effects of LABA and glucocorticosteroids observed in clinical studies.

In summary, formoterol inhibited cytokine release from MDM via interaction with the $\beta_{2}$-adrenoceptor. Similarly, the partial agonist, salmeterol had a limited anti-inflammatory activity in this cell system but did not stimulate intracellular cAMP levels. Taken together, these data suggest alternative activation pathways for $\beta_{2}$-agonists in macrophages that may contribute to the anti-inflammatory actions of these therapeutic agents.

\section{STATEMENT OF INTEREST}

Statements of interest for L.E. Donnelly and P.J. Barnes can be found at www.erj.ersjournals.com $/ \mathrm{misc} /$ statements.dtl

\section{ACKNOWLEDGEMENTS}

This study was funded by AstraZeneca (Lund, Sweden) and by the NIHR Respiratory Disease Biomedical Research Unit at the Royal Brompton and Harefield NHS Foundation Trust and Imperial College London (London, UK).

\section{REFERENCES}

1 Lohmann-Matthes ML, Steinmuller C, Franke-Ullmann G. Pulmonary macrophages. Eur Respir J 1994; 7: 1678-1689.

2 Peters-Golden M. The alveolar macrophage: the forgotten cell in asthma. Am J Respir Cell Mol Biol 2004; 31: 3-7.

3 Tudhope SJ, Finney-Hayward TK, Nicholson AG, et al. Different mitogen-activated protein kinase-dependent cytokine responses in cells of the monocyte lineage. J Pharmacol Exp Ther 2008; 324: 306-312.

4 Barnes PJ. Macrophages as orchestrators of COPD. COPD 2004; 1 : 50-70.

5 Keatings VM, Collins PD, Scott DM, et al. Differences in interleukin- 8 and tumor necrosis factor- $\alpha$ in induced sputum from patients with chronic obstructive pulmonary disease or asthma. Am J Respir Crit Care Med 1996; 153: 530-534.

6 Riise GC, Ahlstedt S, Larsson S, et al. Bronchial inflammation in chronic bronchitis assessed by measurement of cell products in bronchial lavage fluid. Thorax 1995; 50: 360-365.

7 Rutgers SR, Timens W, Kaufmann HF, et al. Comparison of induced sputum with bronchial wash, bronchoalveolar lavage and bronchial biopsies in COPD. Eur Respir J 2000; 15: 109-115.

8 Balbi B, Bason C, Balleari E, et al. Increased bronchoalveolar granulocytes and granulocyte/macrophage colony-stimulating factor during exacerbations of chronic bronchitis. Eur Respir J 1997; 10: 846-850.

9 Profita M, Chiappara G, Mirabella F, et al. Effect of cilomilast (Ariflo) on TNF- $\alpha$, IL-8, and GM-CSF release by airway cells of patients with COPD. Thorax 2003; 58: 573-579. 
10 Chung KF. Cytokines in chronic obstructive pulmonary disease. Eur Respir J 2001; 18: Suppl. 34, 50s-59s.

11 Borish L, Mascali JJ, Dishuck J, et al. Detection of alveolar macrophage-derived IL-1 $\beta$ in asthma. Inhibition with corticosteroids. J Immunol 1992; 149: 3078-3082.

12 Linden $M$. The effects of $\beta_{2}$-adrenoceptor agonists and a corticosteroid, budesonide on the secretion of inflammatory mediators from monocytes. Br J Pharmacol 1992; 107: 156-160.

13 Zetterlund $A$, Linden $M$, Larsson $K$. Effects of $\beta_{2}$-agonists and budesonide on interleukin- $1 \beta$ and leukotriene B4 secretion: studies of human monocytes and alveolar macrophages. J Asthma 1998; 35: 565-573.

14 Hung $\mathrm{CH}$, Chu YT, Hua YM, et al. Effects of formoterol and salmeterol on the production of Th1- and Th2-related chemokines by monocytes and bronchial epithelial cells. Eur Respir J 2008; 31: 1313-1321.

15 Baker AJ, Palmer J, Johnson $\mathrm{M}$, et al. Inhibitory actions of salmeterol on human airway macrophages and blood monocytes. Eur J Pharmacol 1994; 264: 301-306.

16 Seldon PM, Barnes PJ, Meja K, et al. Suppression of lipopolysaccharide-induced tumor necrosis factor- $\alpha$ generation from human peripheral blood monocytes by inhibitors of phosphodiesterase 4: interaction with stimulants of adenylyl cyclase. Mol Pharmacol 1995; 48: 747-757.

17 Smith SJ, Cieslinski LB, Newton R, et al. Discovery of BRL 50481 [3(N,N-dimethylsulfonamido)-4-methyl-nitrobenzene], a selective inhibitor of phosphodiesterase 7: in vitro studies in human monocytes, lung macrophages, and CD8+ T-lymphocytes. Mol Pharmacol 2004; 66: 1679-1689.

18 Culpitt SV, Maziak W, Loukidis S, et al. Effect of high dose inhaled steroid on cells, cytokines, and proteases in induced sputum in chronic obstructive pulmonary disease. Am J Respir Crit Care Med 1999; 160: 1635-1639.

19 Celli BR, Thomas NE, Anderson JA, et al. Effect of pharmacotherapy on rate of decline of lung function in COPD: Results from the TORCH study. Am J Respir Crit Care Med 2008; 178: 332-338.

20 Calverley PM, Boonsawat W, Cseke Z, et al. Maintenance therapy with budesonide and formoterol in chronic obstructive pulmonary disease. Eur Respir J 2003; 22: 912-919.

21 Eickelberg $\mathrm{O}$, Roth $\mathrm{M}$, Lorx $\mathrm{R}$, et al. Ligand-independent Activation of the Glucocorticoid Receptor by $\beta_{2}$-adrenergic receptor agonists in primary human lung fibroblasts and vascular smooth muscle cells. J Biol Chem 1999; 274: 1005-1010.

22 Oddera S, Silvestri M, Testi R, et al. Salmeterol enhances the inhibitory activity of dexamethasone on allergen-induced blood mononuclear cell activation. Respiration 1998; 65: 199-204.

23 Silvestri M, Fregonese L, Sabatini F, et al. Fluticasone and salmeterol downregulate in vitro, fibroblast proliferation and ICAM-1 or H-CAM expression. Eur Respir J 2001; 18: 139-145.

24 Korn SH, Jerre A, Brattsand R. Effects of formoterol and budesonide on GM-CSF and IL-8 secretion by triggered human bronchial epithelial cells. Eur Respir J 2001; 17: 1070-1077.

25 Sapey E, Stockley RA. COPD exacerbations. 2: aetiology. Thorax 2006; 61: 250-258.

26 Winkler AR, Nocka $\mathrm{KH}$, Sulahian $\mathrm{TH}$, et al. In vitro modeling of human alveolar macrophage smoke exposure: enhanced inflammation and impaired function. Exp Lung Res 2008; 34: 599-629.

27 Traves SL, Smith SJ, Barnes PJ, et al. Specific CXC but not CC chemokines cause elevated monocyte migration in COPD: a role for CXCR 2 . J Leukoc Biol 2004; 76: 441-450.

28 Schild HO. pAx and competitive drug antagonism. Br J Pharmacol Chemother 1949; 4: 277-280.

29 Clarke DL, Belvisi MG, Hardaker E, et al. E-ring 8-isoprostanes are agonists at EP2- and EP4-prostanoid receptors on human airway smooth muscle cells and regulate the release of colony-stimulating factors by activating cAMP-dependent protein kinase. Mol Pharmacol 2005; 67: 383-393.
30 Barnes PJ. Scientific rationale for inhaled combination therapy with long-acting $\beta_{2}$-agonists and corticosteroids. Eur Respir J 2002; 19: 182-191.

31 Giembycz MA, Kaur M, Leigh R, et al. A Holy Grail of asthma management: toward understanding how long-acting $\beta_{2}$-adrenoceptor agonists enhance the clinical efficacy of inhaled corticosteroids. Br J Pharmacol 2008; 153: 1090-1104.

32 Gordon S, Taylor PR. Monocyte and macrophage heterogeneity. Nat Rev Immunol 2005; 5: 953-964.

33 Rabe KF, Giembycz MA, Dent G, et al. Salmeterol is a competitive antagonist at $\beta$-adrenoceptors mediating inhibition of respiratory burst in guinea-pig eosinophils. Eur J Pharmacol 1993; 231: 305-308.

34 Scola AM, Chong LK, Suvarna SK, et al. Desensitisation of mast cell $\beta_{2}$-adrenoceptor-mediated responses by salmeterol and formoterol. Br J Pharmacol 2004; 141: 163-171.

35 Maneechotesuwan K, Essilfie-Quaye S, Meah S, et al. Formoterol attenuates neutrophilic airway inflammation in asthma. Chest 2005; 128: 1936-1942.

36 Reid DW, Ward C, Wang N, et al. Possible anti-inflammatory effect of salmeterol against interleukin-8 and neutrophil activation in asthma in vivo. Eur Respir J 2003; 21: 994-999.

37 Kaur M, Holden NS, Wilson SM, et al. Effect of $\beta_{2}$-adrenoceptor agonists and other cAMP-elevating agents on inflammatory gene expression in human airways smooth muscle cells: a role for protein kinase A. Am J Physiol Lung Cell Mol Physiol 2008; 295: L505-L514.

38 Baltathakis I, Alcantara O, Boldt DH. Expression of different NF$\kappa \mathrm{B}$ pathway genes in dendritic cells (DCs) or macrophages assessed by gene expression profiling. J Cell Biochem 2001; 83: 281-290.

39 Farmer $\mathrm{P}$, Pugin J. $\beta$-Adrenergic agonists exert their "antiinflammatory" effects in monocytic cells through the IкB/NF-кB pathway. Am J Physiol Lung Cell Mol Physiol 2000; 279: L675-L682.

40 Zhong $\mathrm{H}$, SuYang $\mathrm{H}$, Erdjument-Bromage $\mathrm{H}$, et al. The transcriptional activity of NF- $\kappa \mathrm{B}$ is regulated by the IкB-associated PKAc subunit through a cyclic AMP-independent mechanism. Cell 1997; 89: 413-424.

41 Scott MG, Swan C, Jobson TM, et al. Effects of a range of $\beta_{2-}$ adrenoceptor agonists on changes in intraceullar cyclic AMP and on cyclic AMP driven gene expression in cultured human airway smooth muscle cells. Br J Pharmacol 1999; 128: 721-729.

42 Munoz NM, Rabe KF, Vita AJ, et al. Paradoxical blockade of $\beta$ adrenergically mediated inhibition of stimulated eosinophil secretion by salmeterol. J Pharmacol Exp Ther 1995; 273: 850-854.

43 Magocsi M, Vizi ES, Selmeczy Z, et al. Multiple G-protein-coupling specificity of $\beta$-adrenoceptor in macrophages. Immunology 2007; 122: 503-513.

44 Ye RD. $\beta$-Adrenergic agonists regulate NF- $\mathrm{BB}$ activation through multiple mechanisms. Am J Physiol Lung Cell Mol Physiol 2000; 279: L615-L617.

45 Giembycz MA, Newton R. Beyond the dogma: novel $\beta_{2-}$ adrenoceptor signalling in the airways. Eur Respir J 2006; 27: 1286-1306.

46 Tanaka Y, Yamashita Y, Yamaki F, et al. Evidence for a significant role of a Gs-triggered mechanism unrelated to the activation of adenylyl cyclase in the cyclic AMP-independent relaxant response of guinea-pig tracheal smooth muscle. Naunyn Schmiedebergs Arch Pharmacol 2003; 368: 437-441.

47 Koike K, Yamashita Y, Horinouchi T, et al. cAMP-independent mechanism is significantly involved in $\beta_{2}$-adrenoceptor mediated relaxation. Eur J Pharmacol 2004; 492: 65-70.

48 Miller-Larsson A, Selroos O. Advances in asthma and COPD treatment: combination therapy with inhaled corticosteroids and long-acting $\beta_{2}$-agonists. Curr Pharm Des 2006; 12: 3261-3279.

49 Usmani OS, Ito K, Maneechotesuwan $\mathrm{K}$, et al. Glucocorticoid receptor nuclear translocation in airway cells after inhaled combination therapy. Am J Respir Crit Care Med 2005; 172: 704-712. 
50 Korn SH, Wouters EFM, Wesseling G, et al. Interaction between glucocorticoids and $\beta_{2}$-agonists: a and b glucocorticoid receptor mRNA expression in human bronchial epithelial cells. Biochemical Pharmacology 1998; 56: 1561-1569.
51 Kaur M, Chivers JE, Giembycz MA, et al. Long-acting $\beta_{2-}$ adrenoceptor agonists synergistically enhance glucocorticoiddependent transcription in human airway epithelial and smooth muscle cells. Mol Pharmacol 2008; 73: 203-214. 